\title{
Research on the Influence of a new kind of Admixture on the Property of Shotcrete
}

\author{
Zi-bo Tang ${ }^{1,2, a}$, Xian-jun Tan ${ }^{*}, 2,3, \mathrm{~b}$, Xiangjun Meng ${ }^{2}$, Fuqi Wang ${ }^{2}$, Weiqing Li ${ }^{2}$, Jiangqing Bian ${ }^{2}$ \\ ${ }^{1}$ College of Mining and Safety Engineering, Shandong University of Science and Technology, Qingdao Shandong \\ 266590, China; \\ ${ }^{2}$ Yanzhou coal co., LTD., Zoucheng, Shandong, 273512, China;
}

${ }^{3}$ China State Key Laboratory of Geomechanics and Geotechnical Engineering, Institute of Rock and Soil Mechanics, Chinese Academy of Sciences, Wuhan, Hubei 430071, China

a961343546@qq.com, bxjtan@whrsm.ac.cn

\begin{abstract}
A new kind of admixture for the shotcrete was proposed, its main ingredient is silica fume $(61.3 \%)$ and bentonite $(38.3 \%)$, plus a small amount of polyacrylic acid $(0.4 \%)$. The influences of the admixture on the liquidity of shotcrete were studied, it is results that: 1 ) with the increase of the cement content, the workability of the shotcrete improves significantly; 2) with the increase of admixture dose, the bleeding rate significantly decreases; 3) after adding admixture, the anti-segregation capabilities are mostly above $95 \%$. Even if the shotcrete with admixture added in has high fluidity, it also has good anti-segregation capability; 4) the shotcrete before adding admixture has much dust around while the dust is obviously decreased after adding admixture.
\end{abstract}

Keywords-concrete admixture; shotcrete; roadway support

\section{INTRODUCTION}

In the early 20th century, Germany developed shotcrete mortar and applied it for roadway support [1-2]. The practice proved that compared with cast-in-place concrete, shotcrete has an advantage of simple and easy construction which avoids the jobs of form erecting, pouring and form removal. At present, shotcrete technology has been widely used in metallurgy, coal and water conservancy industry as well as various underground works for supporting the chambers and road ways [3-5].But, high rebound rate and instability of shotcrete are the long-standing problems with the development of shotcrete. [6]. Though the wet shotcrete method basically solves the problem of the high dust concentration in the air, since wet shotcrete normally requires liquid quick-setting agent, under the working of air pressure, residue of the liquid quick-setting agent is still easily observed in the air, which remains harmful to the workers' body [7-9].

There are several methods to solve the above mentioned problems. First, add more quick-setting agent so as to make the shotcrete sprayed on the rock surface cure rapidly and have no falling any more. But the quick-setting agent prevents the falling of shotcrete and reduces the loss of shotcrete only after the spray, and it doesn't solve the problem of shotcrete loss caused by the rebounded material in the course of spray. Second, add admixtures. Academy of Metallurgical Science has developed a kind of admixture, but this admixture is actually a kind of admixture, which are powders by grinding inorganic minerals. It can't reduce the loss rate of the rebound significantly, let alone to reduce the dust content in the air [10].

Therefore, a kind of specialized admixture for shotcrete is badly to be developed to improve the viscosity of the shotcrete, reduce the loss of rebound and the dust in the working space during the spraying process of the shotcrete and meanwhile thicken the thickness of every spray layer. This paper proposes a new kind of admixture for the shotcrete, and focuses on the study of the influence rules of the admixture on the liquidity of shotcrete.

\section{MATERIALS}

\section{A Cement}

The cement used in this study is a Chinese standard (GB175-2007) 425\# Portland cement [19]. Its density is $3100 \mathrm{~kg} / \mathrm{m} 3$.

\section{B Aggregate}

Coarse aggregate, with a specific gravity of 2.69 and a maximum size of $15 \mathrm{~mm}$, was used. The fine aggregate was washed sand having a specific gravity of 2.65 and a fineness modulus of 2.92 .

\section{Admixture}

An especial self-made admixture was applied in this study. Its main ingredient is silica fume $(61.3 \%)$ and bentonite $(38.3 \%)$, plus a small amount of polyacrylic acid $(0.4 \%)$.

\section{TESTING EQUIPMENT}

- A standard tester for consistency and setting time of the cement (Vicat Apparatus).

- A funnel of cement mortar consistency: produced by Hebei Guanghua Weiye Construction Instrument Factory, with a capacity of $1725 \mathrm{ml}$.

- Multi-function rock mechanics test (RMT) machine: A series of RMT systems was developed [11-12]. The machine has a unique multi-function design and control technology; it can conduct many types of tests such as uniaxial compression, 
triaxial compression, tension, shear and fatigue tests. Its maximum load is $1 \mathrm{MN}$, and its maximum confining pressure is $50 \mathrm{MPa}$.

\section{RESULTS AND DISCUSSION}

\section{A The influence of the admixture on influence rules of the admixture on the liquidity of shotcrete}

Slump and slump flow are used to describe the liquidity of shotcrete in the tests. The results of the influences of the cement content on the liquidity of shotcrete are shown in Table 4.

TABLE I INFLUENCES OF DIFFERENT CEMENT CONTENTS OF THE ADMIXTURE ON THE LIQUIDITY OF SHOTCRETE

\begin{tabular}{|c|c|c|c|c|c|c|}
\hline Water-cement ratio & Cement/kg & Admixture/\% & Slump/mm & $\begin{array}{c}\text { Slump } \\
\text { flow/mm }\end{array}$ & $\begin{array}{c}\text { Bleeding } \\
\text { rate } / \%\end{array}$ & Air content $/ \%$ \\
\hline 0.5 & 380 & 0.5 & 198 & 360 & 5.1 & 4.1 \\
\hline 0.5 & 400 & 0.5 & 220 & 450 & 2.1 & 3.1 \\
\hline 0.5 & 430 & 0.5 & 250 & 480 & 0 & 3 \\
\hline 0.5 & 450 & 0.5 & 240 & 590 & 0 & $>10$ \\
\hline
\end{tabular}

It can be seen from Table 1 that with the increase of the cement content, the workability of the shotcrete improves significantly. As the water-cement ratio is invariant, so the quantity of mixing water is increased accordingly when increasing the cement content. As the water demand of the shotcrete mixed with admixtures will increase obviously, the increase of cement content will also increase the water consumption. Therefore, the increase of the mixing water will not lead to the bleeding and dissociation of the shotcrete, but will make the shotcrete maintain moderate cohesiveness. The increase of the cement content makes the new mixed shotcrete have moderate cohesiveness and liquidity. The application of the admixture improves the water-retaining property of the new mixed shotcrete.

\section{$B \quad$ The influence of the admixture on the bleeding \\ performance of shotcrete}

The bleeding performance of the shotcrete mixed with admixtures is pretty poor, which hardly bleed. This is another characteristic that differs from other shotcretes. The ratio of the fixed tests are: the tests on the relationships between different mixing amounts of admixtures and the bleeding rates under the conditions of the water-cement ratio being 0.5 , the cement content being $400 \mathrm{~kg} / \mathrm{m} 3$, and the sand percentage being 0.4 . The results of the tests are shown in Fig.1.

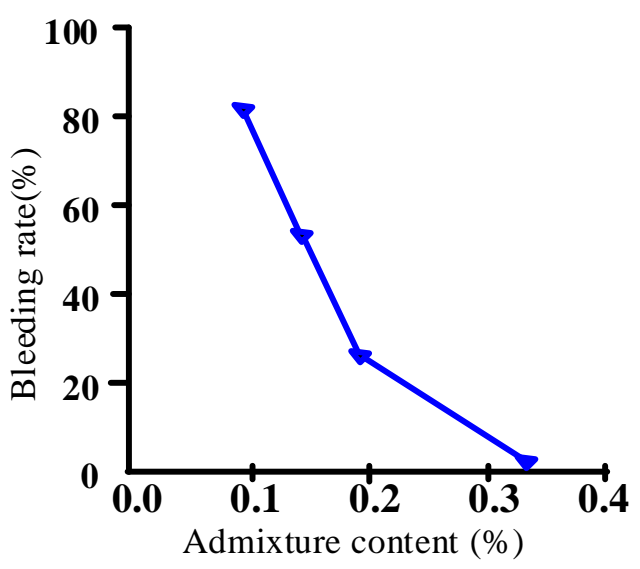

Figure 1. The relation curve of the mixing amounts of admixtures and the bleeding rates

As obviously shown in the data and curve above, under the condition of fixing shotcrete mixture proportion, with the increase of admixture dose, the bleeding rate significantly decreases. When water-cement ratio is 0.5 , cement content is $400 \mathrm{~kg} / \mathrm{m}^{3}$ and the dose of admixture adds to $0.33 \%$, the bleeding rate of shotcrete is 0 , indicating that shotcrete with admixture mixed into has a good water conserving property which is beneficial to the development of shotcrete strength and the delay or decrease of inchoate cracks. 


\section{Influences on the anti-segregation capability of the} influence of admixture on the property of shotcrete
For influences on the anti-segregation capability of the influence of admixture on the property of shotcrete, see Table 2.

TABLE II INFLUENCES ON THE ANTI-SEGREGATION CAPABILITY OF THE INFLUENCE OF

ADMIXTURE ON THE PROPERTY OF SHOTCRETE

\begin{tabular}{ccccccc}
\hline $\begin{array}{c}\text { Test Group } \\
\text { Number }\end{array}$ & $\begin{array}{c}\text { Water-Ceme } \\
\text { nt Ratio }\end{array}$ & Cement/kg & $\begin{array}{c}\text { Sand } \\
\text { Percentage/\% }\end{array}$ & Admixture/\% & Fluidity/mm & Anti-segregation/\% \\
\hline 1 & 0.6 & 400 & 40 & 0.4 & 430 & 9.2 \\
2 & 0.5 & 430 & 40 & 0.1 & 400 & 98.4 \\
3 & 0.4 & 430 & 40 & & 0.9 & 94.9 \\
\hline
\end{tabular}

According to the analysis of test results, after adding admixture, the anti-segregation capabilities are mostly above $95 \%$. Even if the shotcrete with admixture added in has high fluidity, it also has good anti-segregation capability.

\section{$D \quad$ Influences on the rebound rate of the influence of admixture on the property of shotcrete}

Fix the mixture proportion for tests: under the conditions that water-cement ratio is 0.5 , cement content is $400 \mathrm{~kg} / \mathrm{m}^{3}$, sand percentage is 0.4 and that admixture dose is $13.05 \%$ of the cement content, scene conditions before and after adding admixture are shown in Fig. 2 and the test results of dust concentration are presented in Table 3. As seen in both Fig .2 and Table 3, the shotcrete before adding admixture has much dust around while the dust is obviously decreased after adding admixture, which indicates that the influence of admixture on the property of shotcrete and obviously has an effect on reducing the rebound rate.

TABLE III INFLUENCES ON THE REBOUND RATE OF THE INFLUENCE OF ADMIXTURE ON THE PROPERTY OF SHOTCRETE

\begin{tabular}{ccc}
\hline Test Item & Before adding admixture & After adding admixture \\
\hline Dust Concentration $/\left(\mathrm{mg} / \mathrm{m}^{3}\right)$ & 113 & 27 \\
Rebound Rate/\% & 16.8 & 7.3 \\
\hline
\end{tabular}

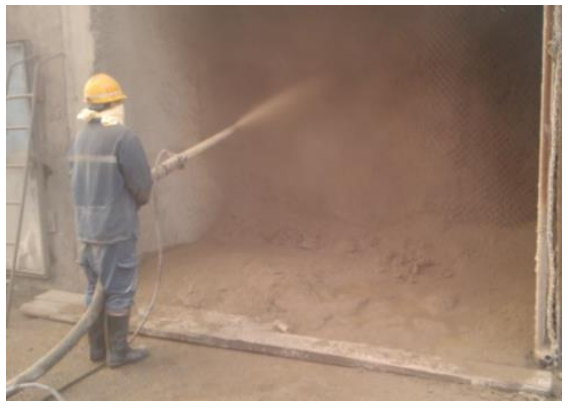

(a) Without adding admixture

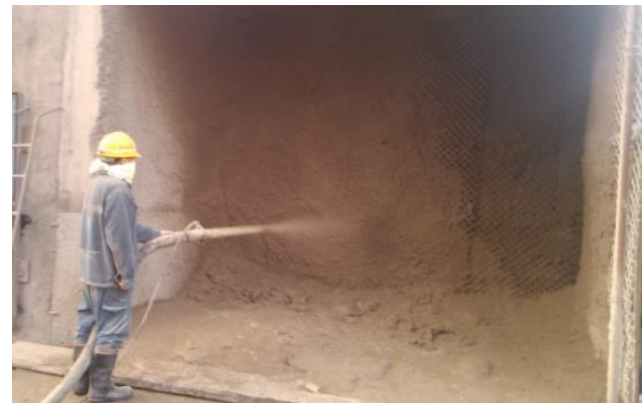

(b) After adding admixture

Figure 2. Effects of admixture on controlling dust

\section{CONCLUSIONS}

A new kind of admixture for the shotcrete was proposed. The influences of the admixture on the liquidity of shotcrete were studied and can be summarized as follows.
1) With the increase of the cement content, the workability of the shotcrete improves significantly.

2) With the increase of admixture dose, the bleeding rate significantly decreases.

3) After adding admixture, the anti-segregation capabilities are mostly above $95 \%$. Even if the shotcrete 
with admixture added in has high fluidity, it also has good anti-segregation capability.

4) the shotcrete before adding admixture has much dust around while the dust is obviously decreased after adding admixture, which indicates that the influence of admixture on the property of shotcrete and obviously has an effect on reducing the rebound rate.

\section{ACKNOWLEDGEMENTS}

This work was supported by the National Program on Key Basic Research Project (973 Program) (Grant Nos. 2015CB057906 and 2013CB036006), the National Natural Science Foundation of China (Grant Nos. 51208499, 41102193 and 51109207), the Postdoctoral Science Foundation of China (2014M550365).

\section{REFERENCES}

[1] J. H. Yang, W. B. Lu, Z. G. Zhao, P. Yan and M. Chen, Safety distance for secondary shotcrete subjected to blasting vibration in Jinping-II deep-buried tunnels. Tunnelling and Underground Space Technology. 43, (2014)

[2] Stanislaw Prusek, Marek Rotkegel and Lukasz Malecki, Laboratory tests and numerical modelling of strength-deformation parameters of a shotcrete lining. Engineering Structures. 75, (2014)
[3] Nicolas Ginouse, Marc Jolin and Benoit Bissonnette, Effect of equipment on spray velocity distribution in shotcrete applications. Construction And Building Materials. 70, (2014)

[4] Nicolas Ginouse and Marc Jolin, Experimental and Numerical Investigation of Particle Kinematics in Shotcrete. Journal Of Materials In Civil Engineering. 26, 0601402311(2014)

[5] Jon Elvar Wallevik, Relationship between the Bingham parameters and slump. Cement And Concrete Research. 36, 7(2006)

[6] Nathan Tregger, Amedeo Gregori, Liberato Ferrara and Surendra Shah, Correlating dynamic segregation of self-consolidating concrete to the slump-flow test. Construction And Building Materials. 28, 1(2012)

[7] Nan Su, Kung-Chung Hsu and His-Wen Chai, A simple mix design method for self-compacting concrete. Cement And Concrete Research. 31, 12(2001)

[8] Nan Su and Miao Buquan, A new method for the mix design of medium strength flowing concrete with low cement content. Cement and Concrete Composites. 25, 2(2003)

[10] X.J., Tan; W.Z., Y.G., Hao. Experimental Study of Ultralight $(<300 \mathrm{~kg} / \mathrm{m} 3)$ Foamed Concrete. Advances in Materials Science and Engineering, 2014.

[11] X.J., Tan; W.Z., G.J., Wu. Degradation characteristics of foamed concrete with lightweight aggregate and polypropylene fiber under freeze-thaw cycles[J]. Magazine of Concrete Research, 65(12): 720-730, (2013) 